\title{
DIGITALCOMMONS
}

- @WAYNESTATE -

Wayne State University

\section{Communicating feelings: Links between mothers' representations of their infants, parenting, and infant emotional development}

Katherine L. Rosenblum

University of Michigan - Ann Arbor

Carolyn Joy Dayton

Wayne State University, carolyn.dayton@wayne.edu

Susan McDonough

University of Michigan

\section{Recommended Citation}

Rosenblum, K.L., Dayton, C. J., \& McDonough, S.C. (2006). Communicating feelings: Links between mothers' representations of their infants, parenting, and infant emotional development. In O. Mayseless (Ed.), Parenting representations: Theory, research, and clinical implications, pp. 109-148. New York: Cambridge University Press.

Available at: http://digitalcommons.wayne.edu/soc_work_pubs/44 
(C) 2006 Cambridge University Press, originally published in O. Mayseless (Ed.), Parenting representations: Theory, research, and clinical implications, pp. 109-148. Deposited by permission (http://www.cambridge.org/about-us/rights-permissions/permissions/permissions-requests-our-authors/) 


\title{
4 Communicating Feelings
}

\section{Links Between Mothers' Representations of Their Infants, Parenting, and Infant Emotional Development}

\author{
Katherine L. Rosenblum, Carolyn J. Dayton, \\ and Susan McDonough
}

\begin{abstract}
In the present chapter we explore how mothers' internal working models of their seven-month-old infants organize emotions in the parenting context, and ultimately, influence infant emotion regulation. We propose that mothers' internal working models of their infants function as emotion regulators, and influence a variety of components of the affective organization of parenting, including a) maternal emotion activation, b) qualities of maternal emotional engagement with their infants, and c) emotion regulation strategies mothers employ during emotionally challenging interactions. Results underscore the important role played by emotional processes in explaining the correspondence between maternal and infant emotion regulation strategies.
\end{abstract}

The relationship with a primary caregiver is the emotional cocoon from which the infant's social and emotional self develops and emerges. Developmentalists from a range of theoretical perspectives have underscored the centrality of the parent-infant relationship for early infant emotional development and emphasize the belief that parent-infant interaction during the earliest months may serve as the foundation for the differentiation of the self (Fonagy, 1999; Mahler, Pine, \& Bergman, 1975; Sameroff \& Emde, 1989; Winnicott, 1965). In other words, the self is born out of relationships and develops as part of, and within, a specific relational context.

Relationships are inherently affective bonds between individuals, and thus, not surprisingly, affective processes play a central role in the attachment and caregiving behavioral systems. For example, during infancy emotional stimuli (e.g., fear reactions/distress) trigger the need for proximity seeking, and infant attachment security reflects, at least in part, the ability to express both positive and negative emotion in the presence of the primary attachment 
figure with the (assumed) expectation that emotional and safety needs will be met (Bowlby, 1969; Thompson \& Lamb, 1984). Parenting is also an inherently emotion-laden process (Dix, 1991), and the caregiving system is similarly activated by emotion (e.g., infant distress promotes parent emotional response that, in turn, triggers caregiving behavior) (Solomon \& George, 1996).

From an attachment perspective, early day-to-day relational experiences have a central role in shaping the infant's social and emotional expectations, eventually generalizing into internal "templates," or "working models," of relationships (Bowlby, 1969; Stern, 1989). There are a variety of factors that may influence the quality of the behavioral level of this interaction, including the manner in which the caregiver perceives and experiences the infant's needs, demands, emerging personality, and future potential. How the parent represents the child and his or her relationship with the child is likely to shape the quality of his or her interpretation of the infant's signals and cues, and thereby guides the caregiving response. This in turn is likely to hold consequences for the emotional tone of the daily "lived moments," and ultimately, the child's emotional security (Cummings \& Davies, 1996; Gergely \& Watson, 1996; Goldberg, MacKay-Soroka, \& Rochester, 1994; Sroufe, 1995).

While much of the extant attachment-based research has focused on parents' representations of their own early relationships and consequences for child attachment security at one year and beyond (e.g., Benoit \& Parker, 1994; Fonagy, Steele, \& Steele, 1991), in this chapter we will explore the role of parents' representations of their infants on parenting and infant emotional development during the first year of life. Our emphasis will be on the role of parenting representations in both reflecting and shaping parents' emotional experience of the child, and subsequent links to caregiving and child emotional development. As reflected in this volume, there are a number of interviews designed to assess parents' representations; in this chapter we focus on one specific interview designed to assess parents' representations of their infant and their relationship with their infant: the "Working Model of the Child Interview" (Zeanah \& Benoit, 1995), and present data from our own work that highlight the important role that may be played by such representations on early infant emotional development.

\section{Infant Emotional Development: The "Relational Cocoon"}

There is a significant and growing literature regarding the importance of the parent-infant relationship for early social-emotional development (Sroufe, 1995). During earliest infancy, the regulation of many of the infant's interoceptive states depends upon the behavior of the caregiver. As the 
infant develops, the repertoire of self-regulating behaviors increases. Emotional development during the first year also reflects this progression, with optimal development moving from the pleasurable feelings associated with the caregiver-assisted regulation of physiological needs to the positive selffeelings and emergent autonomy made possible through the establishment of a secure base with a trusted attachment figure. At each stage in early development, the caregiver is critical in helping the infant successfully negotiate age-salient emotional tasks (Erikson, 1985; Sroufe, 1995). The infant's capacity to signal the caregiver to respond to internal feeling states reflects early infant emotional self-regulation, and success in the use of such signals is likely to lead to feelings of positive affect and efficacy in the modulation of feeling states (Derryberry \& Reed, 1996).

Given the critical role played by the primary caregiver in helping to shape the infants' early emotion-regulation strategies, factors that influence the caregiver's ability to accurately and sensitively identify and respond to infant emotion-cues takes on a particularly important role. Indeed, the impact of parents' affective processes on infant emotional development has been studied from a number of different perspectives (see Rudy \& Grusec, this volume). Multiple aspects of infant emotional behavior, including expressiveness, selfand other-directed emotion regulatory behaviors, and soothability, have been linked, for example, to the parent's own emotional expressiveness (e.g., Garner, 1995), awareness of emotional states (e.g., Gergely \& Watson, 1996), and parental emotional dysregulation (e.g., depression; Field, 1994). We propose that parents' representations of their infants are also important influences on their emotional engagement with their infants, as they reflect and guide parents' emotional responses to their infants (Milligan et al., 2003; Goldberg et al., 1994), and consequently, are likely to provide a critical context for infant emotional development.

\section{Internal Working Models: Organizing and Reflecting the Emotional Experience of Relationships}

Internal working models are mental templates that shape and guide the individuals processing of relational experience. They are organizational constructs, built over time on the basis of lived interactive experience, and are composed of both cognitive and affective elements. Typically internal working models operate outside of conscious awareness (Zimmermann, 1999). Research on adult attachment representations have focused primarily on the individual's current state of mind with respect to early attachment relationships assessed via the Adult Attachment Interview (AAI) (George, Kaplan, \& Main, 1985). Responses to the AAI are thought to yield important information 
about current internal working models of early relationships to primary caregivers. Attachment researchers have proposed that access to relevant emotional experience, without the need to minimize or distort emotional material, distinguishes the secure (autonomous) working model category from other insecure patterns of representation (Main, Kaplan, \& Cassidy, 1985; Zimmermann, 1999). Significant intergenerational correspondence in parent AAI classifications and infant internal working models has been well established (e.g., Benoit \& Parker, 1994; Fonagy, Steele, \& Steele, 1991; van IJzendoorn, 1995).

As reflected in the current volume, however, an area that has been receiving increased attention over recent years is the role of parents' internal working models of parenting, or of their child and relationship with their child, as predictors of parental behavior with the child (Biringen, Matheny, Bretherton, Renouf, \& Sherman, 2000; Slade, Belsky, Aber, \& Phelps, 1999; Solomon \& George, 1996). Researchers have argued for the importance of considering the unique role of the caregiving system, a complementary behavioral system to the infants' attachment system (Solomon \& George, 1996). While research evidence does support the influence of the parent's representation of early caregiving experiences on infant attachment security, these representations are more distal to the parent-child relationship than the caregiver's representation of his or her own child or of parenting. George and Solomon (1996) suggest that during adolescence the individual begins to develop a representation of self as caregiver that is rooted in, or influenced by, the internal working model of early relationships (i.e., their AAI classifications). Evidence suggests that these working models are not redundant, but rather that attachment and caregiving reflect parallel yet distinct behavioral systems. For example, Slade and colleagues (1999) examined whether mothers' representations of parenting mediated the association between AAI classifications and parenting behavior. They found that both AAI classifications and parenting representations were associated with quality of behavioral interaction. Mothers who were more joyful and coherent in their parenting representations were more positive and less negative while interacting with their toddlers. However, the parenting representations did not mediate the link between AAI classifications and behavior, suggesting parenting and representations contribute uniquely to the quality of caregiving and parental emotional displays.

What other evidence supports the conclusion that parents' internal working models of parenting influence their emotional interaction with their infants? To date, there are only a handful of studies directly assessing parents' representations of their infant or of parenting and observations of parent-infant interactive behavior. These include the work by Slade and colleagues (1999) described earlier, and the work of Biringen and colleagues (2000), who found 
that levels of emotional availability in interaction evident when the infant was 18 months of age predicted subsequent maternal sensitivity/insight in the parenting representation when infants were 39 months of age. In our own work we have also examined the link between parents' working models and emotions during parent-child interaction, extending prior work by examining these links when infants were under one year of age. But before we discuss these results, we will turn our attention to providing a more sophisticated model of emotions in parenting.

\section{The Affective Organization of Parenting: Links with Parents' Representations of Their Children}

Psychological research on emotion processes has made significant advances in recent years, providing a more sophisticated conceptualization of affective processes. This work has, however, had relatively little impact on research regarding affective processes in parenting (Dix, 1991), despite the fact that parenting is clearly an emotional (both challenging and pleasing) task. In his review article on the affective organization of parenting, Dix (1991) presents a model of parenting that highlights the central role of affective processes. The three elements of affective organization emphasized are: a) factors that activate particular emotional responses in the parent, b) the role of emotions in orienting, organizing, and/or motivating the parents' behavioral responses to the child, and c) the processes by which parents might control or regulate their emotional responses. To illustrate each of these components, mothers vary in terms of a) how negatively they experience their child's cries, b) how behaviorally sensitive they are in responding to their distressed child, and c) how well they are able to control their displays of distress. In this chapter, we propose an extension of this model, illustrating how parents' working models of their children or of caregiving influence or reflect emotional processes at each of these three levels.

Our perspective on the role of working models as regulators of the affective organization of parenting is consistent with current research and theory in the attachment literature. For example, Zimmermann (1999) has argued that one of the primary functions of internal working models of attachment relationships (i.e., assessed via the AAI) is the "adaptive regulation of negative arousal when feeling insecure" (p. 295), and thus internal working models have a central role in the regulation of emotion in a relational context. We propose that parents' representations of their children and of parenting are important regulators of the emotion experienced by the parent in relation to the child, and subsequently serve as motivational factors for parental behavioral responses. 
Consider the following two vignettes; both are mothers of seven-monthold infants responding to a series of questions regarding aspects of parenting that may be experienced as challenging or difficult.

\section{Vignette \#1}

Interviewer: What about when your child is emotionally upset? Can you recall a specific example?

Mother: Um, usually, I, you know, I told you I suffer from depression and he usually gets upset when I get upset. If he sees me cry, or if he knows that I am crying he usually starts to cry, too.

I: What do you do, at that specific time what did you do with him?

M: $\quad$ Um, try and talk to him and hold him and pull myself together, so that way I can help him ... get, you know, back together with himself.

I: $\quad$ And what did you feel like doing?

M: $\quad$ Um, ... more, more, leaving the room, ... I would rather leave the room and cry than for him to have to see me.

I: What do you feel like?

M: Um, probably embarrassed.

\section{Vignette \#2}

Interviewer: What about your child's behavior now is the most difficult for you to handle?

Mother: $\quad \ldots$ OK, the most difficult to handle ... is when she's overly tired and.... When she goes through her fussiness where, it's just crying and nothing relaxes her. Even a bath. And whatnot - so it's w-when she's really overly tired. Then I have a hard time cause I' $m$ tired at the end of the day, and then I have a hard time with patience. Like, "I've done everything to make you happy - we're on the same routine," you know? That's when it bothers me.

I: And how often does this occur?

M: $\quad$ At most two to three times a week - usually she's very easy.... Put her down she goes out.

I: $\quad$ And what do you feel like doing when your child reacts this way?

M: $\quad$ Call her father (laughs). "Come put your kid down she won't go down for me!" 
I:

M:

I:

M:
And how do you feel when she reacts this way?

It bothers me when she starts getting more and more upset and I can't ... control it. But I also know I'm tired. It usually is when I'm really tired that the little things ... that I wanna sit down and relax and I haven't been able to.... So that's the conflict. So I just have to take a deep breath and say... "It's not gonna be much longer, til I can lay down." And what do you actually do? I'll either - it's come down to where she either... recently she likes to sit up on my lap, or lay down with me. And I grab her big comforter from her bed. And that seems just to soothe her. It's like, she doesn't wanna lay down by herself, so by doing it together we calm down together.

There are several notable aspects of these vignettes with respect to understanding parents' emotion regulation strategies in the context of parenting. Both mothers describe situations that activate, or give rise to negative emotions experienced internally. How the mother actually emotionally engages with her infant appears to differ, and this is likely due, in part, to differences in the effectiveness of their emotion regulation efforts.

In the second vignette, the mother has an open regulation strategy, acknowledging the conflict she experiences and fairly directly describing her frustration and anger (e.g., "that's when it bothers me"). These feelings are not overwhelming, however, and she shows us that she can formulate her actual response in terms of the infant's needs, thus protecting her child from having to face the burden of her internal emotional reaction. Indeed, her behavioral engagement strategy has the dual effect of helping both her infant and herself ("by doing it together we calm down together"). The first vignette is somewhat more problematic. At the level of emotion activation, the mother is quite distressed by her own feelings (e.g., "embarrassed"), and her attempts to keep the depression from directly impacting the child are unconvincing (e.g., note that the child is crying because she is crying). Both of these mothers differ in the level of negative emotion that is activated by their infants' behavior, and their ability to successfully regulate their difficult emotions leads to differences in the quality of emotional engagement with their infants. These two mothers also differ in their working models of their children and the quality of their emotion regulation is consistent with these working model classification differences, an issue we will take up later in this chapter.

Let us now explore the particular ways in which parents' representations of their infants may serve a regulatory role in the activation of emotion, the 
parents' behavioral engagement, or displays of emotion, and in the strategies that parents may consciously or unconsciously use to regulate these emotion displays. We propose that parents' representations are linked to caregiving sensitivity via their influence on multiple elements of affective organization in the parent; parents representations influence the activation of emotion, the engagement of emotional processes, and emotion regulation. We provide a brief summary of current research on working model influences on each of these aspects of the affective organization of parenting before returning to our own research on this topic.

\section{Activation of Emotion}

Activation processes precede, or precipitate, emotion. They reflect the inner subjective qualities that will, in part, determine the emotional response to some external or more objective event. Dix (1991) identifies a number of activation-relevant factors that may predispose a person to experience negative affect in the context of parenting. These include inappropriate developmental expectations, a failure to adopt an empathic or child-focused perspective with the child, malevolent attributions regarding the infant's behavior, feelings of helplessness or lower efficacy, and the lack of effective strategies for eliciting desired child behaviors.

It is likely that parents' internal working models of their relationship with their infant reflect these types of "predisposing" or "subjective" factors, and may increase the likelihood that the parent will experience more negative affect in interaction with the infant. Evidence for this comes from research linking working models with biases in the experience of other emotions. For example, Zeanah and colleagues (1993) demonstrated that mothers AAI classifications were associated with their ratings of infant distress, such that dismissive mothers reported more negative affect in response to the emotionality of distressed infants than other mothers.

\section{Engagement Processes}

Once activated, emotions influence cognitive (e.g., expectations, appraisals) and behavioral (e.g., response tendencies, emotion display) processes (Dix, 1991). Emotion-triggered cognitive processes may alert the person to perceive and evaluate particular features of an event, motivate the person to seek particular outcomes, and/or influence the likelihood of certain behavioral responses. It is generally assumed that parents engage in "emotion-consistent" behavior, and that the link between negative emotion and negative behavior is likely to be stronger than that between positive emotion and behavior (Fredrickson, 
1998; Frijda, 1986). For example, Frijda suggests that emotions are, by definition, associations with urges to act in particular ways, called "specific action tendencies." Extant research on several negative emotions supports this notion, for example, a large body of research revealing that anger is associated with blocked goals, and an accompanying motivation to act to remove the offending "barrier." Similarly, when experiencing fear, the body reacts by mobilizing appropriate autonomic support for the possibility of running (Lazarus, 1991). In other words, through specific action tendencies emotions prepare or mobilize both the body and mind to act in specific ways. Fredrickson (1998), however, has proposed that positive emotions operate differently. While positive emotions do often produce urges to act, they appear to be less prescriptive than negative emotions about the specific nature of the behavior to be enacted. Fredrickson proposes that positive emotions may yield nonspecific action tendencies, and in reviewing extant research, she highlights a "broaden and build" theory of positive emotion, such that positive emotions help the person to broaden cognition (e.g., research linking positive emotion with creative thinking) and build resources (e.g., research linking play with positive emotion and intellectual processes). In sum, research on negative emotions supports the notion of a priming effect, such that negative emotions increase negative expectations, which in turn may increase the likelihood that a parent will behave more negatively than if $s /$ he were not negatively aroused. It is possible that parents' positive emotions help to create an environment that optimizes developmental processes, but in a less isomorphic, direct manner than observed with negative emotion.

The internal working model of the child and the relationship with the child may influence this level of engagement by filtering the degree to which parents identify and orient to emotions in the child, as well as by influencing behavior towards the child. There is some data supporting these hypotheses. Goldberg, MacKay, and Rochester (1994) found that infant attachment classifications were associated with unique patterns of maternal emotion socialization. Specifically, they found that mothers of secure infants attended to the full range of infant affective expressions and responded more often than other mothers, while mothers of avoidant infants were less responsive, particularly to infant negative emotion. Mothers of resistant infants were especially responsive to negative affect, but did show some response to positive affect as well. Milligan et al. (2003) found that maternal attachment classifications were related to the communication of emotion through the manner in which mothers sang songs to their infants. Mothers with dismissive classifications did not modify the playfulness of their singing to adjust to infant distress. Haft and Slade (1989) examined differences in affective attunement (i.e., the mother's ability to match the infant's affective state in contour, intensity, and 
temporal features), and found that mothers with autonomous AAI classifications were more attuned to a wider range of infant affect.

Results from these studies are consistent with current theoretical propositions from both the attachment and the emotion literature. Cassidy (1994) has described three patterns of maternal affective communication that correspond to maternal AAI classifications (open, minimized, and heightened); these patterns have parallels in the two patterns of problematic emotional engagement in the parenting context identified by Dix (1991). For one group of individuals, emotion is deactivated, and the parent is unavailable because she or he does not experience emotion in a manner that motivates empathic responding. For another group, emotions may be too strong, and promote a focus on shortterm goals versus long-term motivational strategies. For example, imagine a parent who "sneaks" away quickly without saying good-bye in order to avoid child crying versus a parent who thinks about how to anticipate and signal departures in order to build a sense of security to handle separations with trust in the parent's eventual return. The research evidence described above generally supports the proposition that dismissive mothers are likely to ignore or reject the infant's emotional cues, while the preoccupied group responds inconsistently, which may reflect, in part, the uncertainty associated with identifying appropriate goals, and responding to short- versus- long-term agendas.

\section{Emotion Regulation Processes}

Consistent with Zimmerman (1999), we suggest that internal working models are themselves emotion regulators that influence the activation and attribution of emotion as well as the manner of behaviorally responding. Thompson (1990) has defined emotion regulation as the acquired strategies of emotion self-management, as well as the variety of external influences by which emotion is regulated. Attachment plays a role at both levels of this process; internal working models may shape the "emotion self-management" process, and attachment figures are likely to be significant external influences on the regulation of emotion. Regarding internal working models, Cassidy (1994) describes the emotion regulation strategies employed by infants with different types of attachment classifications; specifically, avoidant working models employ a deactivating attentional strategy, characterized by affect inhibition or minimization, whereas ambivalent strategies are characterized by affect heightening or enhancement.

Emotion regulation strategies help the individual parent to suppress or cope with negative emotion aroused in the context of caregiving (Dix, 1991). 
For example, once the parent is distressed, how does she or he manage these feelings? Are these feelings displayed? What cognitive, behavioral, and social processes might influence the decision to display, or keep hidden, particular emotional reactions? In order to behave sensitively in challenging situations, the parent must be able to tolerate his or her negative emotions, recognize that they pose a threat to the infant, and employ effective control strategies to regulate the show of distress. Individuals may or may not be consciously aware of these emotion regulation strategies, and may or may not be aware of their effectiveness or lack thereof.

Returning to our two vignettes, recall how differently the mothers responded to a question regarding infant behavior they found difficult or challenging. In the first case the emotions the mother describes are strong, flooding her ability to successfully impose cognitive controls to regulate her behavioral response to the infant. Her working model of the child classification reflects this affect-heightening emotion regulation strategy. In the second vignette, the mother's emotions are accessible, that is, she does not deactivate or dismiss their importance. Nor are these emotions overwhelming, flooding her capacity to regulate her behavioral response to the infant. Rather, she can both acknowledge and display her feelings, and regulate using cognitive controls her behavioral response to the infant. Her working model of the infant classification reflects this open, balanced emotion regulation strategy.

\section{Rethinking Sensitivity: The Role of Emotional Processes}

An abundance of literature has established the importance of interactive patterns and parental behavioral sensitivity as a precursor to infant and child attachment security at one year of age and beyond. In the early and pioneering study on infant attachment relationships, the Baltimore study, Mary Ainsworth and her colleagues (1978) identified parental sensitivity as the primary and significant contributor to the ontogeny of individual differences in infant quality of attachment. On the basis of extensive home visit observations, they determined that parental sensitivity towards the infant was very highly correlated to the infant's attachment classification. While the emphasis Ainsworth and other attachment researchers have placed on sensitive response to the infant is consistent with more current work identifying parental sensitivity as an important predictor of infant and child attachment security, current studies have failed to obtain effect sizes as large as the Baltimore study (Egeland \& Farber, 1984; Grossman et al., 1985; DeWolff \& van IJzendoorn, 1997). 
In response to these concerns, DeWolff and van IJzendoorn (1997) undertook a large meta-analysis examining how maternal sensitivity may be related to infant attachment security. Their results confirmed that parental sensitivity is indeed related to attachment security; however, they observed that the effect size of this association is only in the moderate range.

In the context of this current research, it seems important to ask again What is parental sensitivity? In the Ainsworth system, sensitivity was a higherlevel category, subsuming many qualities of the infants' relational environment (Bretherton, 2000). At a basic level, parental sensitivity reflects the quality of caregiving. Sensitive parents provide adequate, responsive, contingent care to the infant. They create a safe atmosphere that potentiates the optimal development of the child - room to explore safely, learn, play, and seek safety when danger or threat is imminent. However, in addition to the behavioral-specific (responding to child distress with physical action, or nonintrusive engagement) and physical (e.g., setting up a "baby-proof" home environment) qualities, sensitivity incorporates a number of emotion-salient components (Bretherton, 2000). Sensitive parents have an empathic stance towards the infant, such that they are able to identify when the infant needs comfort, and are able to provide assistance as needed, thus helping the infant with the regulation of emotion.

Consistent with current conceptualizations, we propose that sensitivity reflects, in large part, the quality of emotional connection to the child that allows for optimal parenting (Biringen et al., 2000; Emde, 2000). While virtually all parents experience an emotional bond with their infants, the quality of their emotional responses may vary. For example, a sensitive parent likely experiences an empathic response, and is emotionally available to the infant. The ability to identify and tolerate the infant's emotional needs allows for responding accurately, empathically, and in a manner that is "in-tune" with the infant's needs and experiences. This makes possible pleasurable, playful interaction. Insensitive parenting occurs when a parent is emotionally unavailable, either because s/he is detached and uninvolved, or because the emotional response is so strong it floods the parent and overwhelms appropriate, sensitive behavior.

\section{Assessing the "Emotional Dance" between Parents and Infants}

Individual differences with respect to the qualities of the emotional engagement exist from very early on, reflected as differences in the type of "emotional dance" conducted by parent and child. Parents' emotional exchanges with infants tend to follow meaningful patterns of interaction. Stern (1985), for example, has written extensively about his observation of mother-infant 
emotional exchange, noting that the affective interactions have a dynamic "shape" to them, and that patterns of affective engagement vary across mother-infant dyads. The mental health of the infant, Stern suggests, is strongly affected by the synchrony of the interaction.

Emotional exchange has also been proposed to play a central role in the infant's emerging ability to recognize his or her own emotional states, and regulate his or her own emotional arousal (Sroufe, 1995). Gergely and Watson (1996), for example, provide a compelling account of how maternal "affective mirroring" behavior helps infants to develop emotional self-awareness and a capacity for self-regulation of emotion. They propose a model in which the mother's ability to activate, regulate, and engage emotionally is related to the infant's own ability to internalize an understanding of emotional experience. At the level of activation, the mother must accurately perceive the infant's emotions. At the level of regulation, the mother must mentally process and transform the emotion, and subsequently, at the level of engagement, display a "marked" exaggerated response to the infant's emotional displays. The authors speculate regarding the impact of deviant "affect-mirroring" styles, suggesting that parents' own intrapsychic conflicts are likely to impact their ability to respond appropriately to the infant's affective displays. The authors further speculate that parents' own representations of attachment relationships may contribute to their ability to sensitively and appropriately engage in this process. For example, they suggest that mothers whose internal representations of relationships reflect a tendency to over-activate emotional arousal, and whose cognitive controls are flooded by emotional/relational experience, may tend to simply mimic their infants' emotional expression, without processing and transforming the emotion. This "pure mirroring" may consequently escalate the infant's emotional state, having failed to provide the necessary containment and assistance in coping with the experienced emotion.

Assessment of the parent-infant emotional "dance" is made possible via the Still Face procedure. Like the Strange Situation, the Still Face allows for the examination of dyadic interaction in the context of low and high stress, as well as the processes by which parents and infants return to a positive affective state following a brief period of maternal unavailability (i.e., interactive repair). In the Still Face maternal unavailability is simulated by having the parent hold a flat, unresponsive expression for a brief period of time; this is preceded and followed by short episodes of normal face-to-face interaction. The temporary maternal unavailability and lack of responsiveness during this procedure is a reliable stress inducer, even for very young infants (Field et al., 1986; Weinberg \& Tronick, 1996). Many mothers also report feeling distressed by the experience of holding a still, unresponsive, expression while their infants are upset, and as an illustration of the motivational function of emotions, 
research has shown that differences in report of maternal distress during the Still Face correspond to different parenting behaviors during the period following the procedure (Mayes et al., 1991).

There is accumulating evidence that infant response to the Still Face during the first half of the first year of life is associated with attachment security at one year of age (Braungart-Reiker et al., 2001; Cohn et al., 1991; Kogan \& Carter, 1996). For example, Cohn and colleagues (1991) report that six-month-old infants who demonstrated any attempt at positive eliciting behaviors (e.g., smiling, play-face expressions) during the Still Face were more likely to be securely attached at 12 months. Similarly, Kogan and Carter (1996) found that four-month-old infants who displayed more resistance (e.g., crying, lack of soothability) and avoidance (e.g., gaze aversion, turning away from mother) during the period immediately following the Still Face were less likely to demonstrate contact-maintenance, a common feature of secure attachment, during the Strange Situation at 12 months. Finally, Braungart-Reiker and colleagues (2001) found that both maternal sensitivity and infant affect regulation during the Still Face procedure when infants were four months of age predicted infant-maternal attachment classifications at one year. Taken together, these results appear to demonstrate some stability in the emotional precursors of subsequent attachment-related behavior.

We now turn to a presentation of our own work examining how mothers' working models of their seven-month-old infants influence the affective organization of their parenting and the quality of the emotional dance between mother and child.

\section{Representations of the Infant, Maternal Emotion Activation and Expression, and Infant Emotion Regulation: Results from the Michigan Family Study}

In our own work on the Michigan Family Study (MFS) (McDonough, 1994; Rosenblum et al., 2002) we have examined the role of mothers' representations of their infants on maternal behavior and infant emotion regulation. We present here our work examining the links between mothers' representations of their infants and two aspects of emotion in parenting: maternal emotion activation and emotional engagement with their infants, as well as the consequences for early infant emotion regulation.

\section{The Michigan Family Study}

The MFS is a longitudinal study focused on the role played by primary relationships and other contexts in shaping the trajectories of infant behavioral 
regulation from infancy to early childhood. We will report here on data from the first wave of data collection, when infants were seven months of age. The MFS sample includes 258 mothers and infants; however, maternal representational data are available only for the first 100 participants $(N=100)$. Mothers of six-month-old infants were recruited from routine "well-baby" pediatric appointments, and study participants comprised a wide range of demographic and socio-economic circumstances (for more details, see Rosenblum et al., 2002).

The MFS protocol involved a home and laboratory visit when the infants were seven months of age. During the home visit, a trained graduate student assistant interviewed the mother with regard to demographic information and her perceptions of her infant's behavior and development. She also administered a projective test requiring the mother to interpret the emotion being displayed in a series of photographs of infants displaying ambiguous facial expressions, the IFEEL task (Butterfield, Emde, \& Osofsky, 1987).

During the laboratory visit, mothers and infants engaged in a series of videotaped interactive tasks, including the Still Face procedure (Rosenblum et al., 2002; Tronick, 1989). For this procedure the infant was placed in a highchair and his or her mother sat in a swivel chair in front of the highchair. Both maternal and infant behaviors were recorded using separate cameras and split-screen technology. The experimenter was not in the room and gave instructions to the mother through a microphone from behind a one-way mirror. The Still Face was cut short if the infant demonstrated high levels of distress and cried continuously for more than 30 seconds. Four motherinfant dyads did not complete the Still Face procedure, either because the infant was excessively distressed at the outset of the procedure, or because the mother took the infant out of the highchair during the task. Therefore, analyses involving mothers' representations and Still Face behavior data are presented for 96 mother-infant dyads ( $n=96$ ).

Following all interactive tasks, the mothers were interviewed using a modified version of the Working Model of the Child Interview (Rosenblum, Muzik, \& Dayton, 2002; Zeanah \& Benoit, 1995). Infants were cared for in an adjacent room while mothers were interviewed by a trained graduate student research assistant.

\section{Maternal Representations of the Infant: The "Working Model of the Child Interview"}

As noted previously, a number of interviews exist designed to assess parents' representations of parenting. On the MFS we employed an interview designed to assess the parents' representation of the child and the relationship with 
Table 4.1. Representational Typology Categories for the WMCI

\begin{tabular}{|c|c|c|c|}
\hline & Balanced & Disengaged & Distorted \\
\hline $\begin{array}{l}\text { Emotion Regulation } \\
\text { Strategy }\end{array}$ & $\begin{array}{l}\text { Flexible, balanced } \\
\text { integration of } \\
\text { positive and } \\
\text { negative affect. }\end{array}$ & $\begin{array}{l}\text { Emotion deactivation. } \\
\text { Cognitively driven } \\
\text { responses with low } \\
\text { levels of emotional } \\
\text { involvement. }\end{array}$ & $\begin{array}{l}\text { Heightened emotion. } \\
\text { Strong feelings } \\
\text { pervade the } \\
\text { interview. } \\
\text { Emotionally driven, } \\
\text { with low levels of } \\
\text { cognitive control. }\end{array}$ \\
\hline $\begin{array}{l}\text { Representation } \\
\text { of Infant }\end{array}$ & $\begin{array}{l}\text { Infant perceived as } \\
\text { easy or challenging, } \\
\text { but caregiver is } \\
\text { generally accepting } \\
\text { of and enjoys the } \\
\text { infant, and views } \\
\text { challenges as } \\
\text { understandable, } \\
\text { normal } \\
\text { perturbations that } \\
\text { will change. }\end{array}$ & $\begin{array}{l}\text { Infant is either } \\
\text { idealized or } \\
\text { rejected. Caregiver } \\
\text { often emphasizes } \\
\text { infant } \\
\text { independence, and } \\
\text { caregiving } \\
\text { sensitivity and } \\
\text { acceptance of the } \\
\text { infant's needs tend } \\
\text { to be low. }\end{array}$ & $\begin{array}{l}\text { Caregiver typically } \\
\text { emphasizes infant's } \\
\text { dependence. } \\
\text { Narratives often } \\
\text { characterized as } \\
\text { role-reversed, } \\
\text { self-involved, } \\
\text { confused, distracted, } \\
\text { uncertain, or } \\
\text { overwhelmed. }\end{array}$ \\
\hline Coherence & $\begin{array}{l}\text { Narrative is high in } \\
\text { internal consistency } \\
\text { and well-organized. }\end{array}$ & $\begin{array}{l}\text { Low coherence, often } \\
\text { manifested in } \\
\text { contradictions, } \\
\text { failure to support } \\
\text { generalized } \\
\text { descriptions with } \\
\text { memories of } \\
\text { specific events, and } \\
\text { sparse recall. }\end{array}$ & $\begin{array}{l}\text { Low coherence, often } \\
\text { manifested as a } \\
\text { wandering narrative, } \\
\text { low in organization, } \\
\text { insuccinct, with } \\
\text { many unexplained } \\
\text { referents and } \\
\text { multiple } \\
\text { unrecognized } \\
\text { contradictions. }\end{array}$ \\
\hline
\end{tabular}

the child: The Working Model of the Child Interview (WMCI) (Zeanah \& Benoit, 1995). The WMCI is a semi-structured interview designed to capture a parent's internalized perceptions and subjective experience of their child's personality and relationship with their child.

The interview yields both dimensional and categorical data, with ratings on multiple scales reflecting specific qualities of the narrative, and assignment to one main typology classification that reflects both content and process features of the narrative. The three representational typology categories are: balanced, disengaged, and distorted (see Table 4.1). Balanced representations were characterized by emotional warmth and acceptance; sensitive responsiveness to infant needs; coherence, and richly detailed, accessible 
descriptions. Parents in this category provided convincing details and experiences that conveyed their involvement and delight in their relationship with their infant. Disengaged representations were characterized by an emotional aloofness and distance from the infant. Parents in this category were likely to describe their infants in a manner that minimized affective involvement, revealing their tendency to reject their infants' emotional and dependency needs. When expressed, anger was "cool" and rejecting; for example, sarcastic comments or emotionally distancing rejection of the infant's needs for closeness, such as, "he just cries because he's spoiled." Distorted representations were characterized broadly by a distortion imposed on the image of the infant and/or the relationship with the infant. As described by Zeanah and Benoit (1995), distortion refers to an internal inconsistency in the narrative rather than necessarily reflecting a contradiction with putative "objective" reality. Parents in this category were often incoherent, and provided confused, contradictory, bizarre, or "unresolved" descriptions of their infant and their relationship. Unlike their disengaging counterparts, parents in this category tended to express a great deal of "hot" emotional experience, which interfered with their ability to provide a coherent, organized narrative. For example, a parent might describe at great length and with angry intensity their annoyance with the child's sleep problems. Sample WMCI questions, as well as more details regarding the scoring system, are included in Appendix 4.1.

The majority of the mothers met criteria for balanced typology classification $(n=55)$, while the remainder were fairly evenly distributed between the disengaged $(n=22)$ and distorted $(n=23)$ categories. In addition, a subset of the WMCI scores were examined, specifically, those scales assessing the affective tone of the representation of the infant (that is, the "emotional coloring" of the parents' representation of the infant). Only affective tone scales with sufficient variability were included in these analyses, specifically, the joy, anger, indifference, anxiety, and sadness scales.

\section{Mothers' Attributions Regarding Infant Emotion: The IFEEL Task}

Mothers completed the Infant Facial Expressions of Emotions from Looking at Pictures task (IFEEL) (Butterfield, Emde, \& Osofsky, 1987) during the home visit. The IFEEL is a projective test designed to pull for individual differences in verbal responses about emotions seen in babies. The test consists of a set of 30 pictures of infants, and parents are asked to describe in one word the emotion the infant is expressing. Maternal responses were scored according the categorical method, which classifies each response 
as belonging to one of 12 specific emotion categories (e.g., joy, sad, anger, surprise, content, passive, shame, disgust, distress, cautious, interest, and fear). Examination of the psychometric properties of the IFEEL using these scoring techniques was conducted with a sample of mothers of infants between the ages of 3 and 12 months, and results confirmed the adequacy of the psychometric properties of the instrument for use with this population (Appelbaum, Butterfield, \& Culp, 1993).

\section{Maternal and Infant Affective Behavior During the Still Face}

The Still Face has been widely used to examine infant emotion regulation in response to temporary maternal unavailability with infants between two and seven months of age (Rosenblum et al., 2002; Tronick, 1989; Weinberg \& Tronick, 1996). The procedure itself is composed of three brief segments that challenge infant, and presumably parent, affective self-regulation: a first "Free Play" segment during which the mother and infant interact in face-toface play; a second period, the "Still Face," during which the mother holds a still face and is unresponsive to the infant; and a final "Reengagement" episode, during which the mother again interacts in face-to-face play with the infant.

Maternal and infant affective behavior was scored during both the Free Play and Reengagement episodes of the Still Face procedure using a system developed by Miller et al. (2002). Each dimension of infant and maternal interactive behavior was given a global score along a four-point scale from 0 (absent) to 3 (high levels present). Maternal positive affect reflected the degree of positive affect displayed by mothers during interaction with their infants, whereas the anger/hostility score reflected the degree to which mothers rejected their infants' bids or made negative comments directly to or about their infants. The resignation/anxiety scale assessed mothers' apparent tendencies to express negative feelings or anxiety by fidgeting, sighing, retreating from interaction, looking worried, or using a high-pitched tone of voice. Infant affective expression was assessed on two scales: infant negative and infant positive affect. Coders were trained extensively, and efforts were taken to ensure that the same coder did not code both mother and infant behavior. For the initial reliability sample $(n=20)$ there was greater than $80 \%$ exact agreement, and continued double coding at regular intervals was conducted to minimize rater drift. Weighted kappa coefficients for the mother and infant behavior scales on a subset of 50 segments ranged from 0.61 to 0.87 . 
Table 4.2. Conceptual Grid Linking Elements of the Affective Organization of Parenting with Assessment Measures Employed in the Michigan Family Study

\begin{tabular}{|c|c|c|c|}
\hline & Emotion Activation & Emotion Regulation & Emotion Engagement \\
\hline $\begin{array}{l}\text { Illustration in } \\
\text { Parenting: "When } \\
\text { I hear the baby } \\
\text { cry ..." }\end{array}$ & $\begin{array}{l}\text { "How does it make } \\
\text { me feel?" }\end{array}$ & $\begin{array}{l}\text { "Am I overwhelmed by } \\
\text { feeling?" "Do I } \\
\text { distance or deactivate } \\
\text { my feelings?" "Am I } \\
\text { open to experiencing } \\
\text { the feelings without } \\
\text { being overwhelmed?" }\end{array}$ & $\begin{array}{l}\text { "What feelings do I } \\
\text { assume the baby } \\
\text { has?" and "What } \\
\text { feelings do I show?" }\end{array}$ \\
\hline \multirow[t]{2}{*}{$\begin{array}{l}\text { Assessment in the } \\
\text { Parent }\end{array}$} & \multirow[t]{3}{*}{$\begin{array}{l}\text { Content features } \\
\text { of the WMCI: } \\
\text { Affective Tone } \\
\text { Scales }\end{array}$} & $\begin{array}{l}\text { Process features of the } \\
\text { WMCI: Typology } \\
\text { Categories }\end{array}$ & $\begin{array}{l}\text { Projection of infant } \\
\text { emotional experience: } \\
\text { Attributions on the } \\
\text { IFEEL task }\end{array}$ \\
\hline & & $\begin{array}{l}\text { Emotional Displays } \\
\text { during Interaction: } \\
\text { The Still Face } \\
\text { Procedure }\end{array}$ & $\begin{array}{l}\text { Emotional Displays } \\
\text { during Interaction: } \\
\text { The Still Face } \\
\text { Procedure }\end{array}$ \\
\hline $\begin{array}{l}\text { Assessment in the } \\
\text { Infant }\end{array}$ & & $\begin{array}{l}\text { Emotional Displays } \\
\text { during interaction } \\
\text { with mother: The Still } \\
\text { Face Procedure }\end{array}$ & $\begin{array}{l}\text { Emotional Displays } \\
\text { during interaction } \\
\text { with mother: The Still } \\
\text { Face Procedure }\end{array}$ \\
\hline
\end{tabular}

Linking Working Models of the Child with Maternal Emotion Activation and Engagement

We now turn to the results of our analyses linking mothers' working model of the child typology classifications to aspects of maternal emotion activation and engagement. Table 4.2 provides a conceptual grid identifying the elements of affective organization captured by each of our assessment methods. We begin with links between working models and emotion activation, then turn to links between working models and cognitive and behavioral engagement processes, and conclude by linking maternal working models to infant emotion regulation.

Emotion Activation: Associations between the WMCI and the Affective Tone of the Representation

Activation processes precipitate emotion and are determinative of which emotion will be experienced, when it will occur, and how strongly it will be activated. We assume that representations of relationships, as mental templates 
through which relational information is processed, will prime mothers to experience certain types of emotion in relation to thinking about infant behavior and emotional expression. Although the WMCI typology classifications may reflect general cognitive disconnection or deactivating emotional strategies, the specific emotional coloring of the representation may be considered, at least in part, to be independent of these process features of the narrative. For example, mothers may express anger/frustration in a cold, sarcastic (deactivated) manner, in a "hot" over-involved (heightened) manner, or in a well-regulated, coherent and contained (open) manner. In all cases, anger/frustration is manifest, but the regulation strategy varies. Our specific hypotheses were that mothers with balanced representations would be most highly colored by intense feelings of joy, whereas disengaged representations would be associated with lower intensity of positive emotion ratings, coupled with a propensity towards higher levels of (cold) anger. We expected that distorted mothers would show high levels of all emotion, but that they would be higher than the other two groups in their negative affective coloring (i.e., anger and anxiety).

In order to test these hypotheses, we analyzed a subset of the data $(n=35)$ for which there were independent raters for the typology classification versus the affective tone scales. Although separate coders were used for this analysis, it is nonetheless important to note that scores on any particular affective tone dimension did not determine the overall typology classification that parent was assigned. For analyses involving this subset, there were 17 balanced, 10 disengaged, and 8 distorted narratives.

Results indicated differences between the three typology groups both in terms of the valence and the intensity of the affective coloring of the representation in the expected direction (see Figure 4.1).

One-way ANOVAs followed by post hoc comparisons (Bonferonni corrections) revealed that mothers with balanced representations demonstrated higher levels of joy than mothers in either of the other two categories, $F(2,33)=12.86, p<0.01$, and lower levels of anger than mothers in the disengaged categories, $F(2,33)=3.93, p<0.05$. There were no differences between the two non-balanced categories with respect to anger; however, mothers with disengaged representations had representations characterized by more indifference than mothers in either of the other two categories, $F(2,33)=17.65, p<0.01$. Mothers in the distorted category had representations that were colored by the highest levels of internalizing affect; specifically, they had higher levels of anxiety, $F(2,23)=6.69, p<0.01$ and sadness, $F(2,23)=3.77, p<0.05$. 


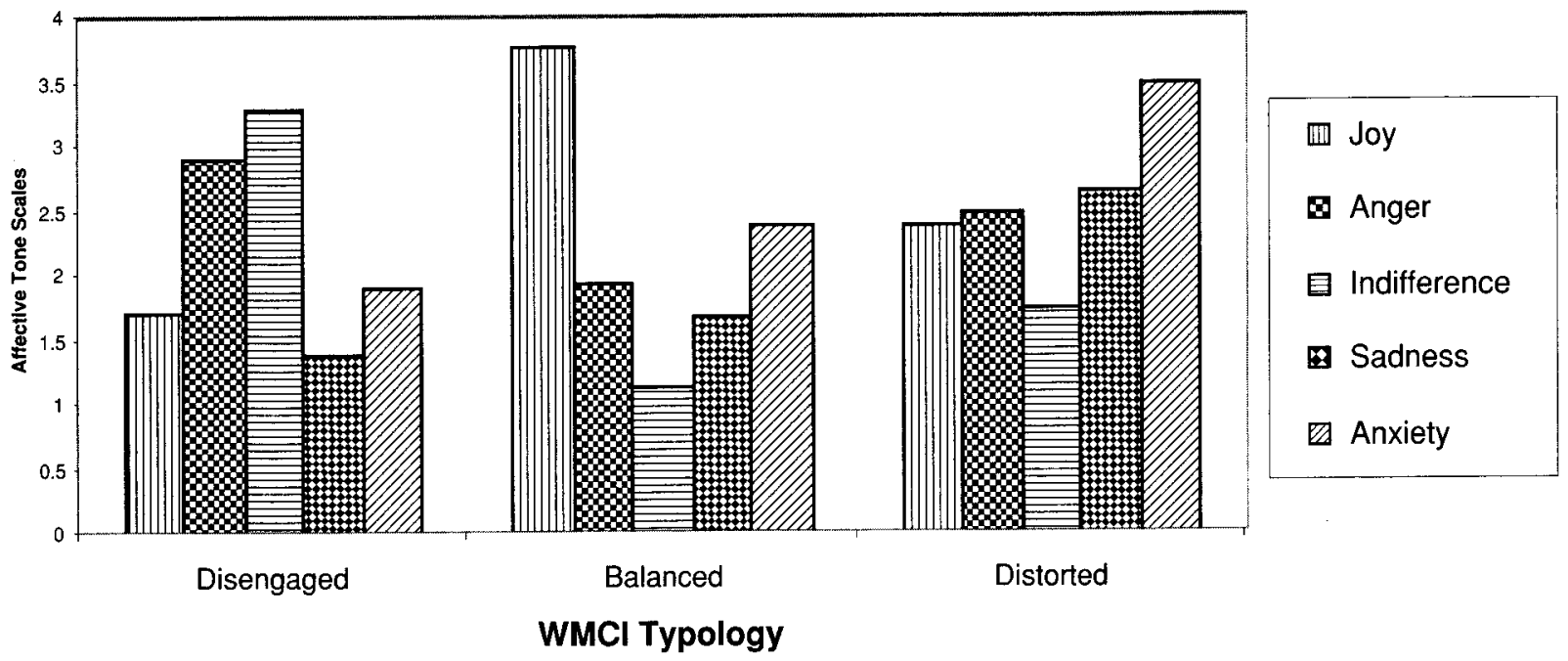

Figure 4.1. The affective tone of mothers' representations of their infants by WMCI typology classifications. 
These results indicated support for our hypotheses. Mothers in the balanced category had representations colored by joy, but on average their representations also included mild levels of anger, sadness, and anxiety. The representations of both non-balanced groups were colored by anger, but in contrast to the indifference evident in the disengaged representations, distorted mothers' representations revealed feelings of anxiety and sadness. Unexpectedly, only the disengaged group had representations that were significantly angrier than the balanced representations. While these findings were generally consistent with Cassidy's (1994) description of open versus deactivated versus heightened affective styles, they diverge from the typical portrayal of disengaged or dismissing mothers as inhibiting affect in general. Rather, these findings appear more consistent with a depiction of disengaged mothers as perhaps experiencing higher levels of internal anger and frustration, which may result from personal feelings of rejection or loneliness. It is possible that, in contrast to distorted mothers, disengaged mothers may be more likely to manifest "cool" anger in their narratives, for example, in the form of sarcasm directed towards the infant, as well as to behave in an emotionally "cool" form of anger during interaction, that is, forms of rejection versus hot angry exchanges. In sum, it was generally apparent that the emotions activated in the context of describing the baby and the relationship with the baby varied according to the mother's internal working model of this relationship.

\section{Emotional Engagement: Associations between the WMCI, Emotion Attributions, and Behavioral Displays}

Our next set of analyses extended this issue by examining the links between mothers working models of their infants and engagement processes. Engagement processes orient, organize, and/or motivate parental emotional behavior in response to the child. Once activated, parental emotions influence cognition (e.g., appraisals) and behavioral (response tendencies) processes. We examined influences on both cognitive and behavioral engagement processes. At the cognitive level, we explored links between mothers' working models of their infants and mothers' emotion attributions on the IFEEL task; at the behavioral level we explored links beween mothers' working models of their infants and their emotional displays during the Still Face.

\section{Working Models of the Infant and Maternal Emotion Attributions on the}

IFEEL. Our next set of analyses examined whether mothers' representations of their infants also influenced the types of attributions they made regarding the emotion displayed by an unknown infant. Our prediction was that mothers 
with balanced representations would attribute more positive valence emotions, while mothers with distorted or disengaged representations would attribute more negative emotions.

In order to test this hypothesis, we conducted a series of one-way analyses of variance with the IFEEL categories as a dependent variable, and mothers' WMCI classifications as the independent variable. Significant WMCI typology differences were observed for three of the IFEEL categories: interest, $F$ $(2,97)=8.50, p<0.01$, cautious, $F(2,97)=4.18, p<0.05$, and anger, $F(2,97)=11.12, p<0.01$. Post hoc comparisons revealed that mothers in the balanced category were more likely to interpret interest $(M=8.13$, $S D=3.37)$ than mothers in the distorted $(M=4.91, S D=2.66)$ category. Similarly, balanced mothers perceived more caution $(M=2.31, S D=1.94)$ than mothers in the disengaged $(M=1.23, S D=1.11)$ or distorted $(M=$ $1.43, S D=1.50)$ categories. Finally, mothers in the disengaged $(M=2.05$, $S D=1.59)$ and distorted $(M=1.75, S D=1.47)$ categories attributed more anger than mothers in the balanced category $(M=0.96, S D=1.10)$.

We also examined the intercorrelations between working model affective tone scales and IFEEL categories, and results indicated a number of significant associations. Joy in the maternal working model of the child was associated with fewer attributions of anger $(r=-0.39)$ and distress $(r=0.20)$ on the IFEEL. Anger in the maternal narrative was associated with more attributions of anger $(r=0.29)$ and passivity $(r=0.20)$, and fewer attributions of interest $(r=-0.28)$ and cautiousness $(r=-0.27)$ on the IFEEL. Indifference in the maternal narrative was associated with more anger attributions $(r=0.32)$ and sadness in the maternal narrative with more sad attributions $(r=0.21)$ on the IFEEL.

Thus, there was mixed support for our hypotheses. Mothers with balanced representations did not make more positive attributions as expected, but they did make more benign attributions regarding ambiguous infant affective displays (i.e., interest). On the other hand, consistent with their tendency to have representations of their own infants that were colored by anger, mothers in the disengaged category attributed more anger to the ambiguous emotion displayed by an unknown infant. Similarly, anger and sadness in the maternal narratives were associated with anger and sadness, respectively, in maternal attributions on the IFEEL. These results are consistent with the notion that links between emotion activation (in this case, the affective tone of the representation) and engagement processes (in this case, attributions) are strongest for negative, as opposed to positive, emotion. Given that the emotion expressions were designed to be "ambiguous," the benign attributions made by mothers in the balanced category may reflect more accurate attributions, while the 
disengaged mothers' projections of anger may reflect more strongly their own negative perceptual biases. It is also possible that disengaged mothers actually experience more "angry" interactions with their infants, in which case these results might be understood not as reflecting projections of internal feeling states per se, but rather, as Magai (1999) has suggested, actual differences in the dyads' prior interactive history.

\section{Working Models of the Infant and Maternal Emotional Display during} the Still Face. We next turned our attention to the question of behavioral engagement, or how mothers communicate their internal feelings to their infants. We were interested in the extent to which mothers might show emotion-consistent parenting behaviors with their own child, and the ways in which these displays might be influenced by infant distress. Our hypotheses were that mothers with balanced representations would demonstrate the highest levels of positive affect in interaction with their infants, while mothers with non-balanced representations would show more negative (angry/hostile and anxious/resigned) emotion during interaction. Because both disengaged and distorted mothers were not differentiated in their levels of anger in the affective tone of the representation, we did not predict differences between these groups in their angry behavior. However, given higher levels of sadness and anxiety in their representations, we expected mothers in the distorted category to display more behavioral level anxiety/resignation. Finally, we anticipated that these differences would be most pronounced following the Still Face during Reengagement, which prior research has demonstrated is a context of heightened infant distress.

In order to test these hypotheses we examined links between mothers' representation (both typology classifications and affective tone scores) and mothers' emotion expression (i.e., joy, hostility/rejection, and resignation/anxiety) during the Still Face procedure, both during the Free Play that precedes the Still Face, and the Reengagement episode following the Still Face $(n=96)$. Results indicated that differences existed in the types of emotions displayed by mothers in each of the representational classification typologies, but that the nature of these associations varied according to the situational context.

Correlational analyses between the WMCI affective tone scales (i.e., joy, anger, indifference, anxiety, and sadness) and maternal affective behavior during the Still Face procedure (i.e., positive affect, anger/hostility, and resignation/anxiety) revealed several significant associations, with patterns varying according to the specific Still Face episode (see Table 4.3). In general, mothers with joyful representations of their infant demonstrated lower levels of anger/hostility, while mothers with representations colored by anger 
Table 4.3. Correlations between Affective Tone Scales and Maternal Affective Behavior during the Still Face Procedure

\begin{tabular}{|c|c|c|c|c|c|c|}
\hline & $\begin{array}{l}\text { Maternal } \\
\text { Positive } \\
\text { Affect } \\
\text { Free Play }\end{array}$ & $\begin{array}{l}\text { Maternal } \\
\text { Positive } \\
\text { Affect } \\
\text { Reengagement }\end{array}$ & $\begin{array}{l}\text { Maternal } \\
\text { Anger/ } \\
\text { Hostility } \\
\text { Free Play }\end{array}$ & $\begin{array}{l}\text { Maternal } \\
\text { Anger/ } \\
\text { Hostility } \\
\text { Reengagement }\end{array}$ & $\begin{array}{l}\text { Maternal } \\
\text { Anxious/ } \\
\text { Resigned } \\
\text { Free Play }\end{array}$ & $\begin{array}{l}\text { Maternal } \\
\text { Anxious/ } \\
\text { Resigned } \\
\text { Reengagement }\end{array}$ \\
\hline \multicolumn{7}{|c|}{ Affective Tone } \\
\hline Joy & .19 & .19 & $-.30 * *$ & -.02 & -.05 & -.15 \\
\hline Anger & -.02 &.$- .30 * *$ & .14 & .10 & -.09 & .09 \\
\hline Indifference & -.17 & $-.27 *$ & $.31^{* * *}$ & -.08 & .11 & .10 \\
\hline Anxiety & -.03 & .11 & -.10 & .11 & .09 & .11 \\
\hline Sadness & .03 & .11 & -.10 & .10 & .18 & $.20 *$ \\
\hline
\end{tabular}

demonstrated less positive affect. Indifference in the representation was associated with both lower positive affect and higher levels of angry/hostile behavior. Finally, representations colored by sadness were associated with higher levels of resignation/anxiety.

In order to examine the association between mothers representational typologies and maternal behavior across the Still Face procedure, a series of repeated measures analysis of variance models were conducted, with maternal behavior codes across the two episodes of the Still Face procedure (i.e., Free Play and Reengagement) as the within subjects factor and maternal WMCI typology category as the between subjects factor.

We began with an analysis of maternal positive affect across the Still Face, and results indicated a significant main effect for positive affect, $F(1,93)=24.64, p<0.001$, although the interaction between WMCI classification and Still Face episode was not significant (see Figure 4.2).

Overall, positive affect decreased for the entire sample from Free Play to Reengagement, with a similar pattern observed for mothers with balanced, disengaged, and distorted WMCI classifications. Notably, the trend was for mothers in the balanced category to show the highest level of positive affect. While a one-way analysis of variance did not yield significant typology group differences in positive affect during the Free Play, at Reengagement mothers with balanced representations showed significantly more positive affect $(M=2.02, S D=0.72)$ than mothers in the disengaged group $(M=1.33$, $S D=0.73), F(2,93)=6.58, p<0.01$.

Our second repeated measures analysis was for maternal anger/hostility across the Still Face procedure, and this time results yielded no main effect. However, results did reveal a significant typology $\times$ episode interaction, $F(2,93)=6.40, p<0.01$ (see Figure 4.3). Post hoc one-way 


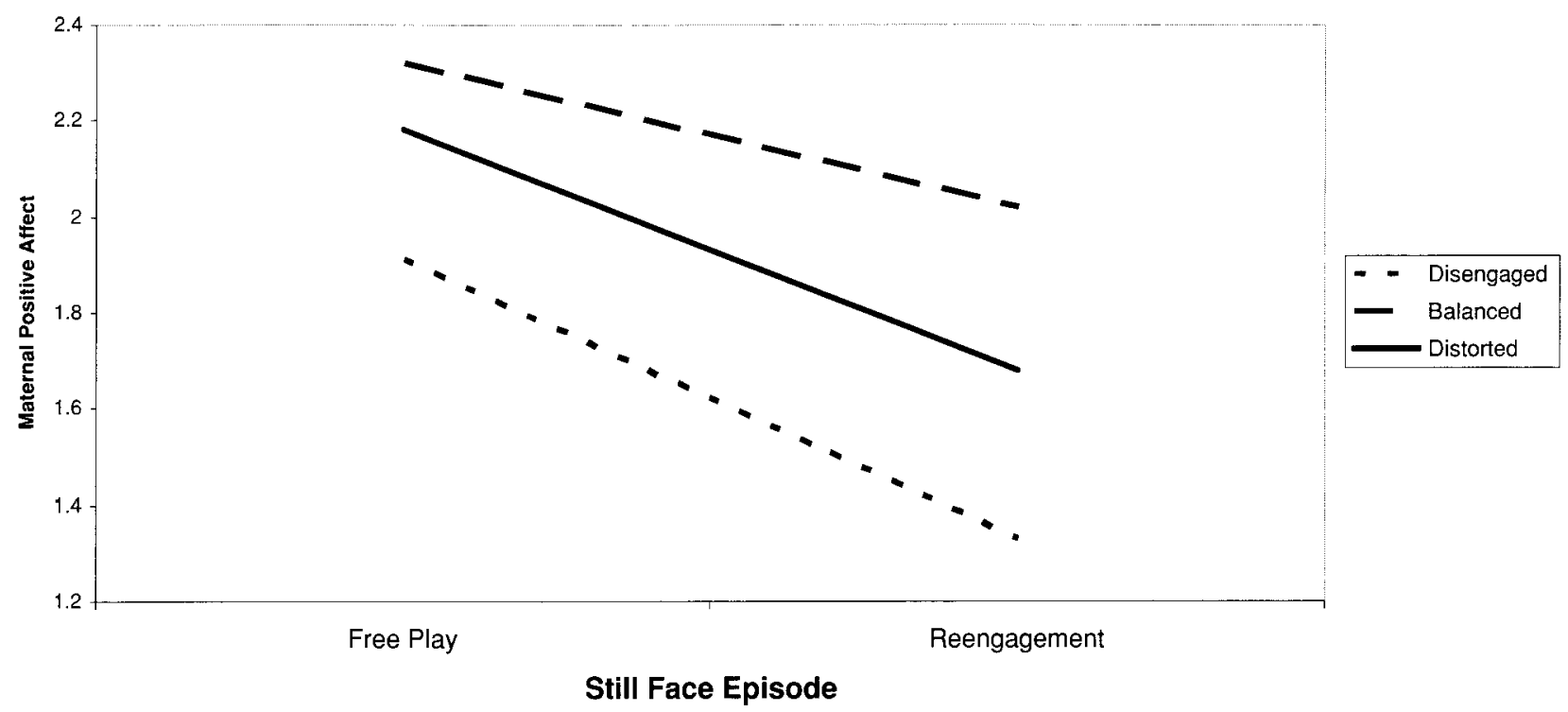

Figure 4.2. Mothers' emotion displays across the Still Face procedure, from the initial Free Play episode to Reengagement following the Still Face: Maternal positive affect. 


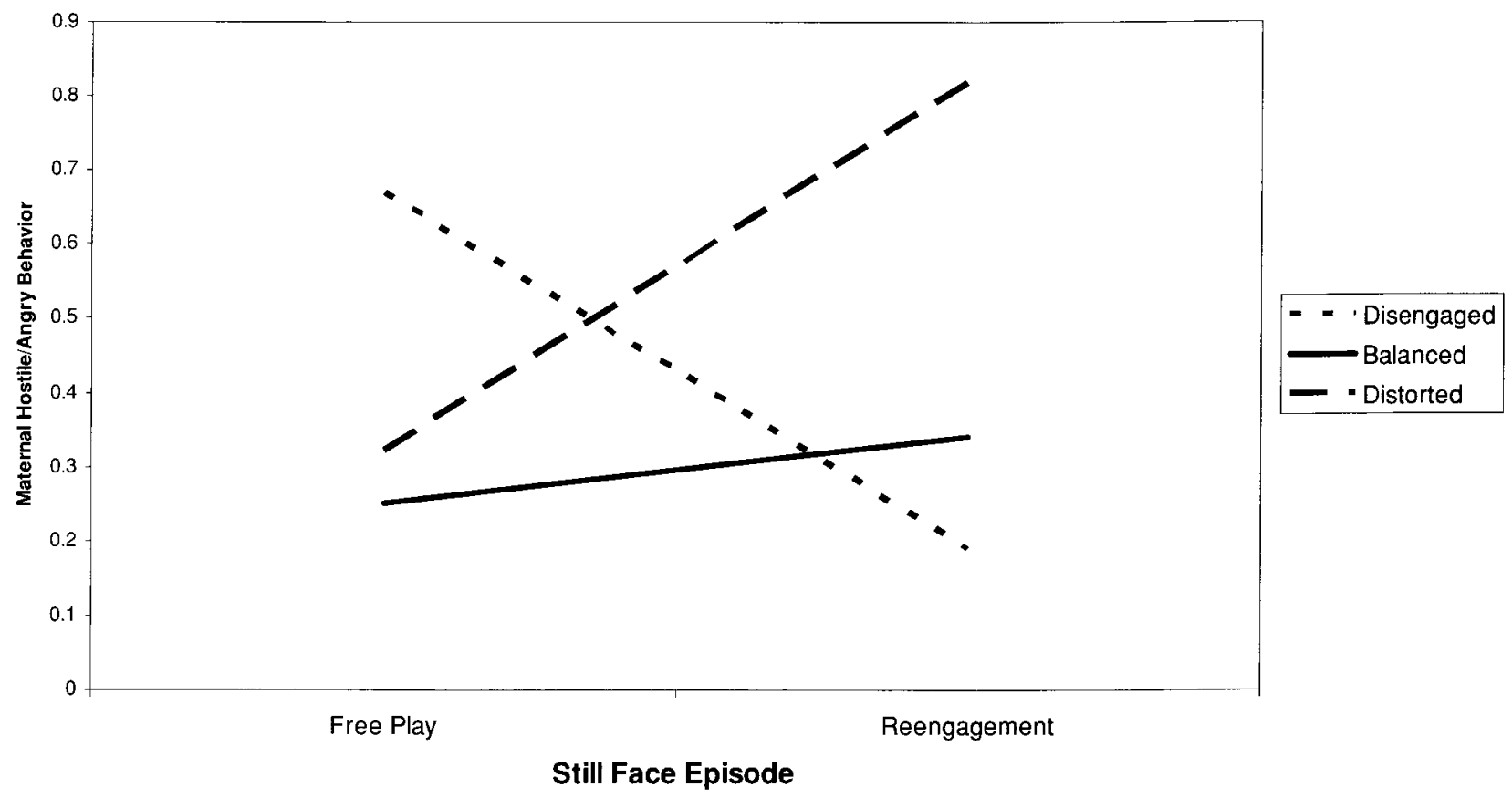

岕

Figure 4.3. Mothers' emotion displays across the Still Face procedure, from the initial Free Play episode to Reengagement following the Still Face: Maternal hostile/angry behavior. 
ANOVAs were conducted separately for each episode, and results indicated that during the Free Play mothers in the disengaged category demonstrated higher levels of anger/hostility $(M=0.67, S D=0.86)$ than the balanced group $(M=0.26, S D=0.44)$, while during the Reengagement mothers in the distorted category demonstrated higher levels of anger/hostility $(M=0.82, S D=1.01)$ than mothers in either the disengaged $(M=0.19$, $S D=0.40)$ or balanced $(M=0.34, S D=0.68)$ groups.

Our third repeated measures analysis did not yield a main effect, nor a significant typology $\mathrm{x}$ episode interaction, for maternal resignation/anxiety across the Still Face episodes.

There was general support for our hypotheses. Mothers in the balanced group demonstrated the highest levels of positive affect, and as predicted, this difference only reached significance in the context of infant distress. Results for displays of angry/hostile behavior yielded a very interesting interaction, such that the anger and hostility displayed by the disengaged mothers decreased from the first to the final Still Face episode, possibly revealing the mothers' tendency to increasingly "disengage" and grow less responsive to their children as their children grew more distressed. Conversely, distorted mothers, who likely experienced heightened affective arousal themselves as their infants grew more distressed, increased in their level of angry/hostile across the episodes. These results appear to be consistent with the findings of Goldberg, MacKay-Soroka, and Rochester (1994), and suggest that balanced mothers respond to the full range of infant emotion with more acceptance and optimism. It appears that mothers with balanced representations had more effective emotion regulation strategies, and thus were better able to cope with their own distress, decreasing their display of positive affect over the course of the Still Face episodes (presumably in an appropriate response to the infants' increased distress), but not increasing in their display of anger or hostility. Mothers in the disengaged and distorted groups, however, appear to utilize less optimal deactivating and heightening strategies in response to infant distress, respectively. Results for the distorted group are particularly interesting in light of the Gergely and Watson (1996) suggestion that certain mothers may "mirror" infant distress too closely, thus failing to provide the infant with the necessary containment and sense of being able to cope with such upset.

"Getting the Message": Links between Mothers' Representations, Affective Displays, and Infant Emotion Regulation

Were these emotional messages received by the infant? We expected that the affective tone of mothers' representations would be linked with 
infant emotion expression during the Still Face procedure. Specifically, we expected higher levels of joy in the mothers' WMCI narrative to be linked with higher levels of infant positive affect, and higher levels of anger/hostility or resignation/anxiety in the mothers' representations to be linked with more infant negative affect. Results of correlational analyses, however, did not support this assumption; there were no significant correlations between mothers' affective tone in the representation and infant emotion displayed during the Still Face procedure.

Elsewhere, we have published data regarding links between the mothers' representational typology classification and infant emotion regulation strategies across the Still Face procedure (see Rosenblum et al., 2002). In contrast to the results for affective tone, we found mothers' representation typologies were indeed associated with differences in infant emotion displayed during the Still Face procedure. Most notably, during the Reengagement infants of mothers with balanced representations demonstrated more positive affect than infants of mothers in either of the other two categories. There was a significant typology $\mathrm{x}$ Still Face episode interaction, such that while all infants displayed lower levels of positive affect during the Still Face, only infants of mothers in the balanced representation category returned to high levels of positive affect upon resuming interaction. Maternal positive affect during the Reengagement mediated the association between mothers' representations and infant positive affect during the Still Face Reengagement.

There is, therefore, some support for the notion that mothers representations and infant emotion regulation strategies are linked, and that maternal emotion displays mediate these associations. However, these results were obtained only for mothers' internal working models of the relationship assessed via the typology score, and not for solitary indicators of the affective tone of the representation. This finding underscores the importance of assessing both the affective and cognitive elements of the working model in order to fully understand how they function together to regulate maternal affective behavior and influence the infants' emotional development. These results also highlight the important and unique role played by positive emotions in developing effective self-regulation strategies.

\section{Conclusions}

Relationships are affective bonds and parenting is an emotionally rich experience. In this chapter we have presented evidence from our own work that suggests that parents' working models of their infants serve as emotion regulators, 
influencing several aspects of parenting, in particular, emotion activation and engagement processes. Our data indicate that parents' representations of their infants, coupled with the emotion-communications that infants experience on a day-to-day basis, influence the infants' emerging self-regulatory capacities. It appears likely that parents' representations underlie this process, influencing not only the way the parent responds at the internal level to the infants' behavioral cues, but also the manner in which the parent responds at the behavioral level to the child during interaction.

Consistent with the work of others who have identified infants' display of positive affect during the Still Face as a predictor of subsequent social-emotional adjustment, our data underscore the importance of parents' positive emotions, both at the level of representation and during interaction with the infant. While a great deal of research has identified problematic or worrisome parenting behaviors defined in terms of the presence of negative, hostile, or rejecting communications, it may be equally important to identify the parents' capacity to experience joy or express positive emotions during interaction with the infant. Parents' parenting representations appear to reflect their ability to contain anxiety and use positive emotion to help their infants regulate distress during a challenging interactive task. Parents' success in using positive emotions to self-regulate is likely to influence their infants' capacity to tolerate expression of both positive and negative emotions, as well as the likelihood that they will use the caregiver to help down-regulate feelings of distress during separation.

The Still Face procedure provides a unique opportunity to observe individual differences in mother-infant interaction in a structured, standardized context. Both the Strange Situation and the Still Face procedure allow examination of the dyads capacity to engage in the process of interactive repair, that is, how the mother and infant negotiate reengagement following a temporary disruption and imposed maternal unavailability. Furthermore, the Still Face allows for observation of interaction during both low and high challenge situations. In our research, we have found that mothers' internal working models of the infant and of the relationship interact with qualities of the task demands, such that low and high challenge situations pull differently for affective displays depending on the quality of the representation.

Given the vast number of expressive interchanges that occur between mother and infant during the first months of life (Magai, 1999), the influence of mothers' working models of their infants as emotion regulators during early interactive episodes is likely to hold significant consequences for infant emotional development, in particular, the development of the infants' own internal working models of relationships. How the mother internally 
represents the infant and the relationship with the infant thus constitutes an integral part of the complex web of relational experience from which the infant develops his or her own social-emotional self.

\section{Appendix 4.1}

\section{The Working Model of the Child Interview}

The interview used for research described in the present chapter is a modified version (Rosenblum, Muzik, \& Dayton, 2002) of the "Working Model of the Child Interview" (WMCI; Zeanah \& Benoit, 1995). The WMCI is a semi-structured interview designed to capture a parent's internalized perceptions and subjective experience of their child's personality and relationship with their child. A number of adaptations to the Zeanah and Benoit (1995) interview were made, including omitting questions regarding early infant development, and inserting questions regarding current family experiences that the parent perceives as particularly stressful or difficult. The WMCI requires an average of one hour to complete and interviews are audio-taped and transcribed for coding purposes.

\section{Validity}

Extant research on the WMCI indicates good external validity, with links to infant attachment classification and clinical status. For example, Benoit, Parker, and Zeanah (1997) found high degrees of correspondence between WMCI classifications and 12-month-old Strange Situation attachment classifications, both for prenatal WMCI classifications (reported concordance 74\% compared to 54\% expected by chance) and WMCI classifications based on interviews conducted when infants were 11 months old (reported concordance $73 \%$ compared to $55 \%$ expected by chance). Similarly, Sims, Hans, and Bernstein (1996) examined correspondence between WMCI ratings and 18-month-old attachment status among a sample of high-risk, inner city African American mothers, and found significant associations between WMCI ratings and infant attachment security. Specifically, mothers whose WMCI classification was "balanced" (corresponding to the AAI autonomous pattern) were more likely to have infants classified as secure on the Strange Situation (reported concordance 64\%). The degree of correspondence between WMCI and SS classifications reported by Sims et al. (1996) is somewhat lower than reported by Benoit, Parker, and Zeanah (1997); this may be in part due to the lower number of "balanced" mothers and "secure" infants in the former, high-risk study sample.

The WMCI has also been found to reliably discriminate clinical versus nonclinical samples of infants (e.g., Coolbear \& Benoit, 1999; Benoit, Zeanah, 
Parker, Nicholson, \& Coolbear, 1997). For example, Benoit et al. (1997) reviewed results from a series of studies comparing the WMCI classifications of a sample of mothers of infants with sleep disorders, failure-to-thrive, or mothers of infants being seen in a general psychiatric clinic to the WMCI classifications of a matched, non-psychiatric control group. Clinical subjects were more likely to have non-balanced representations of the infant; however, the authors did not observe group differences between the two subtypes of non-balanced classifications.

\section{Sample WMCI Questions}

Parents are asked to describe in detail their child's individual characteristics, personality and development, as well as characteristics of their relationship with their child. They are also asked to describe their own emotional reactions and behavior in response to their child in a variety of pleasurable and challenging contexts. The interview is designed to activate both semantic and episodic memory systems in addition to eliciting a wide range of potentially emotionally laden reactions and experiences. Following are some sample questions from the WMCI, selected to illustrate questions focused on the child's personality and behavior, the relationship with the child, the parents' openness to change and future expectations, and integrative questions.

Child's personality and behavior

- Describe what you think of your child's personality now. What is s/he like?

- I'd like you to pick five words or phrases to describe your child's personality. Followed by:

- What is it about [your child] that makes you say that?

- Now can you please give me a specific example that would illustrate what you mean by [word/phrase]?

- What about your child's behavior now is the most difficult for you to handle? Can you give me a typical example? Followed by:

- What do you feel like doing when your child reacts this way?

- How do you feel when your child reacts this way?

- What do you actually do?

Future expectations

- When you worry about [your child] what do you worry most about?

- As you look ahead, what will be the most difficult time in your child's development? 
Integrative questions

- How do you feel your relationship with your child has affected your child's personality?

- Knowing what you know now, if you started all over again with your child, what would you do differently?

\section{Coding}

The coding scheme presented here is drawn largely from the system developed by Zeanah and Benoit (1995) for use with the WMCI. While Zeanah and Benoit have developed a "coherence" scale for use with the WMCI, in our work we have assessed the parent's narrative coherence using scales drawn from the Family Story Collaborative Project (FSCP; Fiese et al., 1999). Additional scales were developed by the present authors for use on the Michigan Family Study (Rosenblum, Muzik, \& Dayton, 2002).

All of the dimensions coded from the narrative transcripts were scored along a five-point scale reflecting the characteristic level of each quality across the entire interview; thus, each parent received only one score for each scale. Each dimension is scored such that higher values reflect the greater presence of the quality reflected in the scale title. Following is a brief description of each of the WMCI scales being used for the present investigation.

Eighteen scales were scored, each falling into one of three broad categories. 1) Infant-and relationship-salient codes capture specific aspects (both manifest and latent) of the parent/infant relationship; 2) Narrative coherence codes assess the organization and internal consistency of the narrative; and 3) Affective tone codes reflect the differential "affective coloring" of the representation.

\section{Infant- and Relationship-Dimensions of the Representation}

Richness of Perception (Zeanah \& Benoit, 1995)

Assesses how richly elaborated the descriptions of the infant are, with higher scores reflecting the parent's greater sense of "knowing" and "being able to describe" the infant.

\section{Caregiving Sensitivity (Zeanah \& Benoit, 1995)}

Reflects the parent's ability to recognize and respond to the infant's emotional and physical needs and experiences. High scores reflect the parent's recognition of the infant as experiencing a range of emotional states and 
biological needs, and a consistent, convincing willingness to respond to these needs.

Acceptance of the Infant (Zeanah \& Benoit, 1995)

Captures the degree to which the parent's representation of the infant is colored by rejection (low ratings) or acceptance and genuine delight in the infant (high ratings).

Resentment of the Parenting Role (Rosenblum, Muzik, \& Dayton, 2002)

Indicates the degree to which the parent feels overburdened by and resentful of the parenting role, with high scores reflecting greater resentment and low scores reflecting acceptance and enjoyment of the parenting process.

Intensity of Involvement (Zeanah \& Benoit, 1995)

Assesses the caregiver's psychological preoccupation with the infant and/or the caregiver's psychological immersion in the relationship and in parenting. High scores reflect clear, consistent, and striking affective engrossment, while low scores reflect a lack of psychological involvement with the infant.

Infant Difficulty (Zeanah \& Benoit, 1995)

Reflects the caregiver's perception of the infant as difficult to care for and understand. Scores reflect both direct statements made by the caregiver, as well as indirect indications (e.g., sarcasm, hostility) that the caregiver experiences the infant as difficult.

\section{Openness to Change (Zeanah \& Benoit, 1995)}

Reflects the flexibility of the representation to accommodate new information about the infant. Scores at the low end of the scale reflect rigidity of the caregiver's perceptions, and a sense that the caregiver would resist incorporating new information in order to maintain a particular point of view.

Helplessness in Parenting (Rosenblum, Muzik, \& Dayton, 2002)

Captures the degree to which the parent experiences herself as being vulnerable or helpless. Parents with high scores tend to describe themselves as inadequate, lacking resources, or powerless in response to the infant and 
parenting demands. On the low end of this scale, parents appear highly efficacious and able to cope with almost all situations.

Impact of Regulatory Processes on Parental Functioning (Rosenblum, Muzik, \& Dayton, 2002)

Indicates whether the mother has explicitly reported concern regarding her infant's crying, sleeping, or feeding behavior, with high scores reflecting the degree to which concerns about the infant's behavior have begun to affect the parent's feelings about the infant, or the relationship between the parent and infant.

\section{Narrative Coherence}

Internal Consistency (Fiese et al., 1999)

Refers to the presence or absence of contradictions in the parent's narrative. Narratives rich in uncontradicted detail that include synthesizing statements regarding the parent's perception and experience of the infant score at the high end, while parents who make contradictory statements regarding their perceptions of the infant, or who fail to support their generalizations with convincing evidence receive low scores.

\section{Organization (Fiese et al., 1999)}

Refers to the structure and "understandability" of the narrative. Organized narratives are concise, on-topic, and the story being told is easily understood. Indices of low organization include the tendency to wander off topic, make unexplained references, and provide too much information. The subject may need the assistance of the interviewer in order to make the narrative understandable.

\section{Affective Tone of the Representation of the Child (Zeanah \& Benoit, 1995)}

A series of scales are scored in order to assess the affective tone of the caregiver's representation of the infant, or the degree to which the rater perceives the particular affective tone "colors" the caregiver's representation of the infant. Low scores reflect the absence of the affective quality in the narrative, while high scores reflect extreme coloring of the representation by the particular affective quality. Note that these scores are not based on what the parent 
says per se, but rather, the rater's perception that the representation is characterized by each particular affective quality. The following affective scales were scored: Joy, Anger, Anxiety, Indifference, Sadness, Guilt, and Fear for Infant's Safety.

\section{WMCI Typology Classifications (Zeanah \& Benoit, 1995)}

In addition to the 18 individual scale dimensions, each narrative was assigned to one of three categories, which represent different representational typologies.

\section{Balanced}

Balanced representations are characterized by emotional warmth and acceptance, sensitive responsiveness to infant needs, coherence, and richly detailed, accessible descriptions. These parents seem to "know" their infant in an essential way, and provide convincing details and experiences that convey their involvement in the relationship and delight in the infant. Although parents in the balanced category may experience feelings of challenge or difficulty in parenting the infant, such issues and concerns do not overwhelm the parents' ability to cope, and have not come to dominate the parents' perception of the infant. Characteristic of this group of parents is the accessibility of a range of emotions, without the need to minimize or the tendency to be overwhelmed by the experience of feelings regarding the infant and the relationship.

\section{Disengaged}

Disengaged representations are characterized by an emotional aloofness and distance from the infant. Parents in this category are likely to describe their infant in a manner that minimizes psychological involvement, and may reveal the parents' rejection of the infant's emotional and dependency needs. They may idealize the relationship with the infant, but are often unable to support these idealizations with specific episodic memory accounts. Repressed hostility and anger are frequent, manifesting in the form of cool distancing and rejection of the infant.

\section{Distorted}

Distorted representations are characterized broadly by a distortion imposed on the representation of the infant and/or the relationship with the infant. Parents in this category are often very incoherent, in the sense of providing confused, contradictory, or bizarre descriptions of the infant and the relationship. Parents 
in the distorted category may be confused and unsure about their relationship with the infant, or anxiously overwhelmed by the infant's perceived needs and experiences. They may be role-reversed in the relationship with the infant, describing the young baby as a "buddy" and "confidant," thus revealing a tendency to place the emotional burden of the relationship on the infant.

\section{References}

Ainsworth, M. D. S., Blehar, M.C., Waters, E., \& Wall, S. (1978). Patterns of Attachment: A Psychological Study of the Strange Situation. Hillsdale, NJ: Erlbaum.

Appelbaum, M. I., Butterfield, P. M., \& Culp, R. E. (1993). Operating characteristics and psychometric properties of the IFEEL pictures. In Emde, Osofsky, \& Butterfield (Eds.), The IFEEL Pictures: A New Instrument for Interpreting Emotions. Madison, CT: International Universities Press, pp. 97-126.

Benoit, D. \& Parker, K. C. H. (1994). Stability and transmission of attachment across three generations. Child Development, 65, 1444-56.

Benoit, D., Parker, K. C. H., \& Zeanah, C. H. (1997). Mothers' representations of their infants assessed prenatally: Stability and association with infants' attachment classifications. Journal of Child Psychology and Psychiatry and Allied Disciplines, $38,307-13$.

Benoit, D., Zeanah, C. H., Parker, K. C. H., Nicholoson, E., \& Coolbear, J. (1997). "Working Model of the Child Interview": Infant clinical status related to maternal perceptions. Infant Mental Health Journal, 18, 107-21.

Biringen, Z. Matheny, A., Bretherton, I., Renouf, A., \& Sherman, M. (2000). Maternal representation of the self as parent: Connections with maternal sensitivity and maternal structuring. Attachment \& Human Development, 2, 218-32.

Bowlby, J. (\{1969\} 1982). Attachment and Loss. Vol. I. Attachment. New York: Basic Books.

Braungart-Rieker, J. M., Garwood, M. M., Powers, B. P., \& Wang, X. (2001). Parental sensitivity, infant affect, and affect regulation: Predictors of later attachment. Child Development, 72, 252-70.

Bretherton, I. (2000). Emotional availability: An attachment perspective. Attachment \& Human Development, 2, 233-41.

Butterfield, P. M., Emde, R. N., \& Osofsky, J. D. (1987). IFEEL Pictures Manual. The Regents of the University of Colorado.

Cassidy, J. (1994). Emotion regulation: Influences of attachment relationships. In N. Fox (Ed.), Biological and Behavioral Foundations of Emotion Regulation. Monographs of the Society for Research in Child Development, 59, 228-49.

Cohn, J. F., Campbell, S. B., \& Ross, S. (1991). Infant response in the still-face paradigm at 6 months predicts avoidant and secure attachment at 12 months. Development and Psvchopathology, 3, 367-76.

Coolbear, J. \& Benoit, D. (1999). Failure to thrive: Risk for clinical disturbance of attachment. Infant Mental Health, 20, 87-104.

Cummings, E. M. \& Davies, P. (1996). Emotional security as a regulatory process in normal development and the development of psychopathology. Development and Psychopathology, 8, 123-39. 
Derryberry, D. \& Reed, M. A. (1996). Regulatory processes and the development of cognitive representations. Development and Psychopathology, 8, 215-34.

DeWolff, M. \& van IJzendoorn, M. H. (1997). Sensitivity and attachment: A metaanalysis on parental antecedents of infant attachment. Child Development, 68, 571-91.

Dix, T. (1991). The affective organization of parenting: Adaptive and maladaptive processes. Psychological Bulletin, 110, 3-25.

Egeland, B. \& Farber, E. A. (1984). Infant-mother attachment: Factors related to its development and changes over time. Child Development, 55, 753-71.

Emde, R. N. (2000). Next steps in emotional availability research. Attachment \& Human Development, 2, 242-8.

Erikson, E. (1985). Childhood and Society, 35th Anniversary Edition. New York: W.W. Norton.

Field, T. (1994). The effects of mother's physical and emotional unavailability on emotion regulation. In N. A. Fox (Ed.), The Development of Emotion Regulation: Biological and Behavioral Considerations. Monographs of the Society for Research in Child Development, 59 (2-3, Serial No. 240), 208-27.

Field, T., Vega-Lahr, N., Scafidi, F., \& Goldstein, S. (1986). Effects of maternal unavailability on mother-infant interactions. Infant Behavior and Development, $9,473-8$.

Fiese, B. H., Sameroff, A. J., Grotevant, H. D., Wamboldt, F. S., Dickstein, S., \& Fravel, D. L. (1999). The stories that families tell: Narrative coherence, narrative interaction, and relationship beliefs. Monographs of the Society for Research in Child Development, 64 (2, serial no. 257).

Fonagy, P. (1999). Psychoanalytic theory from the viewpoint of attachment theory and research. In J. Cassidy \& P. Shaver (Eds.), Handbook of Attachment: Theory, Research, and Clinical Applications. New York: Guilford Press, pp. 595-624.

Fonagy, P., Steele, H., \& Steele, M. (1991). Maternal representations of attachment during pregnancy predict the organization of infant-mother attachment at one year of age. Child Development, 62, 891-905.

Fredrickson, B. (1998). What good are positive emotions? Review of General Psychology, 2, 300-19.

Frijda, N. H. (1986). The Emotions. Cambridge: Cambridge University Press.

Garner, P. W. (1995). Toddlers' emotion regulation behaviors: The roles of social context and family expressiveness. The Journal of Genetic Psychology, 156, 417-30.

George, C., Kaplan, N., \& Main, M. (1985). Adult Attachment Interview. Unpublished manuscript, University of California, Berkeley.

Gergely, G. \& Watson, J. S. (1996). The social biofeedback theory of parental affectmirroring: The development of emotional self-awareness and self-control in infancy. International Journal of Psychoanalysis, 77, 1181-212.

Goldberg, S., MacKay-Soroka, S., \& Rochester, M. (1994). Affect, attachment, and maternal responsiveness. Infant Behavior and Development, 17, 335-9.

Grossman, K., Grossman, K. E., Spangler, G., Suess, G., \& Unzer, L. (1985). Maternal sensitivity and newborns' orientation responses as related to quality of attachment in northern Germany. In I. Bretherton \& E. Waters (Eds.), Growing points of attachment theory and research. Monographs of the Society for Research in Child Development, 50 (1-2, Serial No. 209), 233-57. 
Haft, W. L. \& Slade, A. (1989). Affect attunement and maternal attachment: A pilot study. Infant Mental Health Journal, 10, 157-72.

Kogan, N. \& Carter, A. S. (1996). Mother-infant reengagement following the Still-Face: The role of maternal emotional availability in infant affect regulation. Infant Behavior and Development, 19, 359-70.

Lazarus, R. S. (1991). Emotion and Adaptation. New York: Oxford University Press.

Magai, C. (1999). Affect, imagery, and attachment: Working models of interpersonal affect and the socialization of emotion. In J. Cassidy \& P. Shaver (Eds.), Handbook of Attachment: Theory, Research, and Clinical Applications. New York: Guilford Press, pp. 787-802.

Mahler, M. S., Pine, F., \& Bergman, A. (1975). The Psychological Birth of the Human Infant: Symbiosis and Individuation. New York: Basic Books.

Main, M., Kaplan, N., \& Cassidy, J. (1985). Security in infancy, childhood, and adulthood: A move to the level of representation. In I. Bretherton \& E. Waters (Eds.), Growing points of attachment theory and research. Monographs of the Society for Research in Child Development, 50 (1-1, Serial No. 209), 66-106.

Mayes, L. C., Carter, A. S., Egger, H. L., \& Pajer, K. A. (1991). Reflections on stillness: Mothers' reactions to the still-face situation. Journal of the American Academy of Child and Adolesecent Psychiatry, 30, 22-8.

McDonough, S. C. (1994). Preventing mental health problems in multirisk infants. National Institute of Mental Health RO1 Grant Proposal, University of Michigan.

Miller, A., McDonough, S., Rosenblum, K. L., \& Sameroff, A. J. (2002). Emotion regulation in context: Situational effects on infant and caregiver behavior. Infancy, 3 , 403-33.

Milligan, K., Atkinson, L., Trehub, S. E., Benoit, D., \& Poulton, L. (2003). Maternal attachment and the communication of emotion through song. Infant Behavior and Development, 26, 1-13.

Rosenblum, K. L., McDonough, S., Muzik, M., Miller, A., \& Sameroff, A. (2002). Maternal representations of the infant: Associations with infant response to the Still Face. Child Development, 73, 999-1015.

Rosenblum, K. L., Muzik, M., \& Dayton, C. A. (2002). Working Model of the Infant Interview: 7-Month Version-Revised. Unpublished manuscript: University of Michigan, Ann Arbor.

Sameroff, A. J. \& Emde, R. (1989). Relationship Disturbances in Early Childhood: A Developmental Approach. New York: Basic Books.

Sims, B. E., Hans, S. L., \& Bernstein, V. (1996, April). Inner City Mothers' Working Models of Their Toddlers. Paper presented at the 10th biennial meetings of the International Conference on Infant Studies, Providence, Rhode Island.

Slade, A., Belsky, J., Aber, J. L., \& Phelps, J. L. (1999). Mothers' representations of their relationships with their toddlers: Links to adult attachment and observed mothering. Developmental Psychology, 35, 611-19.

Solomon, J. \& George, C. (1996). Defining the caregiving system: Toward a theory of caregiving. Infant Mental Health Journal, 17, 183-97.

Sroufe, L. A. (1995). Emotional Development: The Organization of Emotional Life in the Early Years. Cambridge, UK: Cambridge University Press.

Stern, D. N. (1985). The Interpersonal World of the Infant: A View from Psychoanalysis and Developmental Psychology. New York: Basic Books. 
Stern, D. N. (1989). The representation of relational patterns: Developmental considerations. In A. J. Sameroff \& R. N. Emde (Eds.), Relationship Disturbances in Early Childhood. New York: Basic Books, pp. 52-69.

Thompson, R. (1990). Emotion and self-regulation. In R. A. Thompson (Ed.), Nebraska Symposium on Motivation, 1988: Socioemotional Development. Lincoln: University of Nebraska Press, pp. 367-467.

Thompson, R. \& Lamb, M. E. (1984). Assessing qualitative dimensions of emotional responsiveness in infants: Separation reactions in the Strange Situation. Infant Behavior and Development, 7, 423-45.

Tronick, E. Z. (1989). Emotions and emotional communication in infants. American Psychologist, 44, 112-19.

van IJzendoorn, M. H. (1995). Adult attachment representations, parental responsiveness, and infant attachment: A meta-analysis on the predictive validity of the Adult Attachment Interview. Psychological Bulletin, 117, 387-403.

Weinberg, K. M. \& Tronick, E. Z. (1996). Infant affective reactions to the resumption of maternal interaction after the still-face. Child Development, 67, 905-14.

Winnicott, D. (1965). The Maturational Processes and the Facilitating Environment. New York: International Universities Press.

Zeanah, C. H. \& Benoit, D. (1995). Clinical applications of a parent perception interview in infant mental health. Infant Psychiatry, 4, 539-54.

Zeanah, C. H., Benoit, D., Barton, M., Regan, C., Hirschberg, L. M., \& Lipsitt, L. (1993). Representations of attachment in mothers and their one-year-old infants. Journal of the American Academy of Child and Adolescent Psychiatry, 32, 278-86.

Zimmermann, P. (1999). Structure and functions of internal working models of attachment and their role for emotion regulation. Attachment and Human Development, 3 , 291-306. 